\title{
LABORATORY MEASUREMENT OF RIVETING HAMMER VIBRATION
}

\author{
TW McDowell, C Warren, DE Welcome, RG Dong \\ Health Effects Laboratory Division, National Institute for Occupational Safety and Health \\ (NIOSH), Morgantown, WV, USA
}

\section{Introduction}

As part of a collaboration with the United States Air Force (USAF) 72nd Aerospace Medicine Squadron (72 AMDS), Bioenvironmental Engineering Flight at Tinker Air Force Base (AFB) in Oklahoma, the Physical Effects Research Team (PERT) of the National Institute for Occupational Safety \& Health (NIOSH) is studying vibration emissions of riveting hammers used in aircraft assembly and maintenance. The PERT team is involved with the ongoing systematic development of new methodologies for evaluating handtransmitted vibration exposures and effects. Among those efforts, PERT has completed studies on chipping hammers, ${ }^{1}$ impact wrenches, ${ }^{2}$ and other powered hand tools. Therefore, an examination of riveting hammer vibrations fits in well with PERT's mission. In this initial study, ten riveting hammers were evaluated in the NIOSH laboratory. Weighted and unweighted vibration data were collected at the tool handles and at the tool operators' ring fingers. The tools were rank-ordered by vibration magnitude for each measurement method. The rank orders generated by the different vibration measurement criteria were then compared.

\section{Methods}

The percussive tool test setup used in this study was that specified in the ISO standard for the measurement of vibrations at the handles of chipping hammers and riveting hammers (ISO 8662-2, 1992). ${ }^{3}$ The test apparatus features an energy absorber that comprises a steel tube filled with hardened steel balls. (See Fig. 1.) When the percussive tool operates, the energy absorber provides a dynamic reaction force which enables stable and reproducible tool action.

Ten brand-new riveting hammers were evaluated in this study. Piezoelectric triaxial accelerometers were used to measure the vibrations. Accelerometers were installed on mounting blocks and secured to the tool handles with hose clamps. An adapter-mounted accelerometer was also secured to the operator's ring finger with a Velcro strap. The accelerometer mounts are depicted in Fig. 1.

Six healthy males served as tool operators. Each operator stood on a force measurement plate/platform and applied a downward push force on the

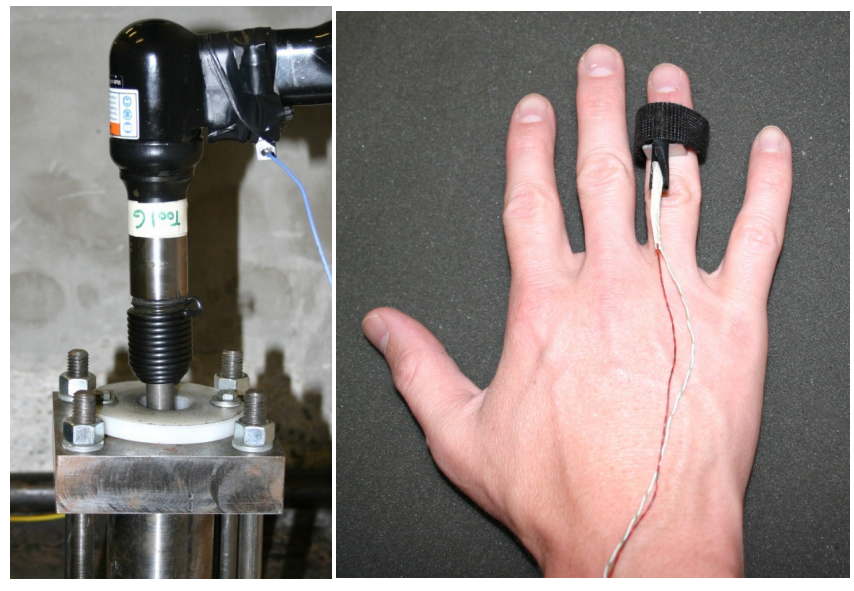

Fig. 1. Tools were operated against the energy absorber specified in ISO 8662-2. Vibration data were collected at the tool handle and at the operator's ring finger. 
tool handle. The tool operators were instructed to apply a feed force of $100 \pm 20 \mathrm{~N}$. A computer monitor displayed a full-screen force strip chart so that the tool operator could monitor and control the feed force during tool operation. The tool operators completed five consecutive 10-second trials with each tool. Tool order was randomized among the operators. Tool handle and finger vibration data were collected simultaneously. The vibration data were expressed as the root-mean-square (r.m.s.) values of the accelerations in the 1/3-octave frequency bands, with center frequencies from 10 to $1,250 \mathrm{~Hz}$. The 'total' values of the r.m.s. accelerations were computed with and without frequency weighting per the ISO 5349-1 standard. ${ }^{4}$

\section{Results, Discussion, and Conclusions}

The rank-orders of the ten tools for each of the four vibration measurement criteria are presented in Table 1. The rankings are based on the averages of the six tool operators. Tools $\mathrm{E}$ and $\mathrm{A}$ were consistently ranked with the lowest vibration regardless of tool operator, measurement location (tool or finger), or acceleration weighting (ISO-weighted or unweighted), and Tools $\mathrm{H}$ and $\mathrm{D}$ were among the highest vibration. The rankings of the other tools were somewhat inconsistent among the ranking criteria. However, it appears that any of the four ranking criteria would be acceptable for initial tool screening. Particularly, the rankings based on weighted accelerations measured on the tool and finger were fairly consistent.

Tool selection should not be based solely on laboratory vibration measurements. Field studies should be conducted to verify or refine tool selection. Other criteria such as productivity, tool versatility, worker acceptance, initial cost, and maintenance costs should

Table 1. The rank orders of the ten tools from 1 (lowest) to 10 (highest) vibration by each of the four ranking criteria.

\begin{tabular}{ccccc}
\hline & \multicolumn{4}{c}{ Ranking Criteria } \\
\cline { 2 - 5 } Rank & $\begin{array}{c}\text { ISO-Weighted } \\
\text { Tool Vib. }\end{array}$ & $\begin{array}{c}\text { Unweighted } \\
\text { Tool Vib. }\end{array}$ & $\begin{array}{c}\text { ISO-Weighted } \\
\text { Finger Vib. }\end{array}$ & $\begin{array}{c}\text { Unweighted } \\
\text { Finger Vib. }\end{array}$ \\
\hline 1 & E & E & E & A \\
2 & A & A & A & E \\
3 & F & B & F & B \\
4 & J & F & J & F \\
5 & C & J & C & J \\
6 & B & I & G & G \\
7 & I & C & B & C \\
8 & D & G & I & H \\
9 & G & D & D & D \\
10 & H & H & H & I \\
\hline
\end{tabular}

also be considered during tool selection.

It is emphasized that ISO 8662 laboratory tool tests are designed for screening tools; these standards are not designed to measure the acceleration values for risk assessment. Therefore, acceleration values obtained via such laboratory testing should not be used for assessing workplace vibration exposures.

\section{References}

1. Dong, R.G., McDowell, T.W., Welcome, D.E., Warren, C. and Schopper, A.W. (2004). An evaluation of the standardized chipping hammer test specified in ISO 8662-2, 1992. Ann Occup Hyg. 48, 39-49.

2. McDowell, T.W., Marcotte, P., Warren, C., Welcome, D.E. and Dong, R.G. (2009). Comparing three methods for evaluating impact wrench vibration emissions. Ann Occup Hyg. 53, 617-626.

3. ISO. (1992). ISO 8662-2, 1992: Hand-held portable power tools -- measurement of vibrations at the handle -- part 2: Chipping hammers and riveting hammers. International Organization for Standardization, Geneva, Switzerland.

4. ISO. (2001). ISO 5349-1: Mechanical vibration -- measurement and evaluation of human exposure to handtransmitted vibration -- part 1: General requirements. International Organization for Standardization, Geneva, Switzerland. 